\title{
A simple conceptual model for coupled hydrological-hydraulic simulation in large basins with significant flood-propagation effects.
}

\author{
César Álvarez ${ }^{1}$, Eduardo García ${ }^{1 a}$, Jorge Rojo ${ }^{1}$, Beatriz Tejerina ${ }^{1}$, Cristina Prieto ${ }^{1}$ and David Fariña ${ }^{2}$ \\ ${ }^{1}$ Environmental Hydraulics Institute "IHCantabria". Parque Científico y Tecnológico de Cantabria, C/ Isabel Torres, 15, 39011 Santander, \\ Cantabria. Spain. \\ ${ }^{2}$ Dirección General de Protección y Conservación de Recursos Hídricos. Secretaría del Ambiente. Paraguay
}

\begin{abstract}
This paper presents a model based on the combination of two simple conceptual sub-models, one for hydrology and one for hydraulics, which is capable of representing the discharges of large river basins with significant wave propagation effects in a lumped and efficient way, using a limited number of parameters (5-6 in the tested case). The model rests on the assumption that a large river basin can be represented as a rectangular region with a certain width-to-length ratio; the main river flows along the length of the rectangle and all the tributaries amount to a lateral uniform flow per unit width. The lateral inflows are represented by the lumped Logistic Equilibrium Model (LEM), while the flow evolution along the main river is given by the analytical solution to the Hayami equation with a uniform lateral inflow, as presented by Moussa (1996). The new model, has been successfully applied in the Tebicuary River at Villa Florida (Paraguay) with 20,400 $\mathrm{km}^{2}$ and compared with the Muskingum routing model, relying only on mean daily precipitations and potential evapotranspiration as input data. The proposed model is computationally efficient, easy to calibrate and open-source (Matlab version).
\end{abstract}

\section{Introduction}

Modelling river discharges can be generally accomplished by selecting and calibrating a hydrological model; lumped or conceptual models can usually provide good estimates with a low number of parameters (4-6). However, in large basins with gentle slopes, as is the case of many regions of the Amazon, Orinoco and ParaguayParaná Basins in South America, flood propagation is a complex and relevant phenomenon, and standard hydrological models fail to reproduce the slowlymodulated patterns of flow evolution, especially in the middle and lower reaches of large basins $\left(>10000 \mathrm{~km}^{2}\right)$.

The most widespread packages for hydrological analysis (e.g. HEC-HMS, SWAT, MIKE-SHE, VIC, etc.) as well as the aggregated hydrological models (PDM, IHACRES, GR4J, NAM, for naming a few) do not allow the hydrographs to be accurately propagated (although they do provide some approximate solutions, which in many cases are acceptable), and therefore requires another external model to carry out this task (IHCantabria, 2019).

This forces the modeller into having to combine hydrological and hydraulic models, creating more complexity and bringing into play local information (topography, grain sizes), which is often not available.

To circumvent this problem, the Institute of Hydraulic Research (in Portuguese, Instituto de Pesquisas Hidraulicas, IPH) of the Federal University of Rio Grande do Sul (UFRGS) has developed the MGB-IPH model, described in Collischonn et al. (2007) and Allasia et al. (2006), which has been successfully used in several Brazilian rivers. On the other hand, Yamazaki et al. (2011) proposed the CaMa-Flood model, coupled to the VIC model, to perform wave propagation in the river channels.

However, the previous models need a large amount of data to be properly implemented. In environments that are rich in data and resources (both human and computational ones), that is hardly a matter of concern, but there are many instances when a simpler and more parsimonious approach is desirable.

In this paper, a combined hydrologic-hydraulic model is presented, merging a lumped hydrological model, the Logistic Equilibrium Model or LEM (Prieto et al., 2013), with a hydraulic model based on the diffusive wave equation (equation of Hayami, Moussa 1996). The main goal is to develop a model that minimizes the parameters needed to reproduce the key processes and, when possible, with a physical meaning, so that they can be extrapolated with certain guarantees to ungauged basins. These criteria are not met by the Brazilian model MGB-IPH, Collischonn et al. (2007), which requires a high number of parameters that are difficult to establish a priori, or by the Yamazaki et al. (2011), which has only been used, with mixed results, for much larger basins. 


\section{Description of the LEM-DIF model}

The proposed model, which will be called LEM-DIF (Logistic Equilibrium Model with DIFfusive wave propagation), is a conceptual lumped model based on discretizing the whole basin into a set of elements or hydrological units (sub-basins) arranged in a tree structure, according to the network topology. Each of these units is formed by a main river and a symmetrical lateral tributary area with respect to the main river, and rectangular shape (Figure 1).

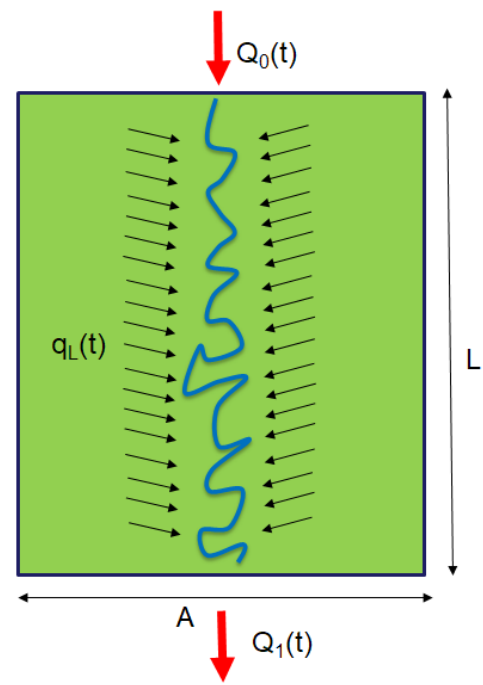

Figure 1. Conceptual scheme of the basic element of the LEMDIF hydrological model.

The associated territory generates runoff through multiple river channels of minor order, that are incorporated as a homogeneous lateral inflow $\left(q_{L}\right)$ per unit valley length of the main river. It is assumed that the lateral basins are steeper and with a shorter length, and are incorporated into the main river using a standard routing method (constant lag or unit-hydrograph approach). All the complex wave propagation effects occur along the main river, and therefore $q_{L}$ can be obtained by means of a conventional lumped model, in this case the LEM (although any other model could be coupled, such as PDM, NAM, GR4J, HYMOD, HBV, etc.).

This approach separates into two coupled sub-models the classic hydrological processes (net rainfall calculation, soil wetting and drying dynamics and simple routing), on the one hand, and processes of a hydraulic nature (diffusive wave solution), on the other. The hydrological units assimilable to this conceptual scheme must meet the following series of a priori requirements:

- The basin must be sufficient large and with a low slope, so that propagation times are larger than the timestep used for the simulation. In the proposed application with daily timestep (see section 3) the units have to be approximately larger than $10^{3} \mathrm{~km}^{2}$ ( $>30 \mathrm{~km}$ long), so that the propagation time is of several days.

- The basins that flow into the main river must have a size of an order of magnitude lower than the whole basin and its propagation effects must be able to be represented with a simple routing model.

- It is generally recommended that the aspect ratio (average length / width) of the basin is greater than 1.5-2. This criterion is somehow redundant with the previous one.

- It is convenient, although not necessary, that the basin is as symmetrical as possible with respect to the main river.

The two sub-models that make up the LEM-DIF model, the conventional hydrological sub-module using the Logistic Equilibrium Model (LEM) and the propagation sub-module that solves the Hayami equation or diffusive wave (DIF), are briefly hereafter.

\subsection{Logistic Equilibrium Model (LEM)}

The Logistic Equilibrium Model or LEM (Prieto et al., 2013 ) is a lumped hydrological model based on two fundamental hypotheses:

1. Watersheds, under theoretical conditions of stationary land uses and climate, tend to an equilibrium runoff coefficient, governed by a Budyko-type expression.

2. In real (non-stationary) conditions, the basins pursue equilibrium following a general law of limited growth (logistic equation).

Instead of subdividing the hydrological problem into several reservoirs as in other mechanistic, lumped models, it considers the whole basin as a non-divisible system which swells and decays according to the supply of rainfall and the evapotranspiration conditions, and draining into a river section using the logistic growth equation (Malthus, 1798; Verhulst, 1838).

The evolution variable we would like to predict is the specific discharge (i.e. total discharge per unit of drainage area) at the basin outlet, and the exogenous variables are the precipitation $(P)$ and the potential evapotranspiration $(P E T)$, or a proxy of it such as the daily maximum temperature $(T)$.

Within the framework of growth equations, the specific discharge represents a sort of population of the hydrological system, which is fed by the rainfall and is limited by the evapotranspiration. The most important element to support this isomorphism is the existence of a "carrying capacity" in the hydrological system that we designate as "equilibrium discharge" $\left(Q_{e q}\right)$. Such equilibrium discharge reflects the maximum water flux attainable in a watershed when a combination of the climatic variables $P$ and $P E T$ remain constant over a long enough time span. In other words, it is assumed that hydrological systems have a stable equilibrium point given by a certain function of $P$ and $P E T$, which varies with time.

The other parameter needed to complete the isomorphism is an intrinsic growth rate of the hydrological system, i.e. how fast the pursuit of equilibrium takes place. In the basic logistic model within the population dynamics framework, growth rate is equivalent to a birth rate: each individual engenders a certain amount of other individuals. 
In a watershed, the discharge needs to be fed by the rainfall and rainfall interacts with the existing water in the system to induce growth in the measured outflows. The strength of the interactions between the existing water in the basin (represented by the state variable $Q$ ) and the rainfall supply (represented by the equilibrium discharge $Q_{e q}$ ) is given by a product of both variables. Finally, all the variables including the precipitation $\left(P\right.$ and $\left.Q_{e q}\right)$ are lagged by an amount $\tau$, reflecting a constant routing time. The final model is governed by the following equation:

$$
\frac{d Q(t)}{d t}=\frac{k \cdot Q(t)}{C_{e q}(t-\tau)} \cdot\left(Q_{e q}(t-\tau)-Q(t)\right)
$$

where $Q(t)$ is the discharge and $Q_{e q}(t)$ is the equilibrium flow derived from multiplying the equilibrium runoff coefficient by the instantaneous rainfall $Q_{e q}(t)=P(t)$. $\mathrm{C}_{\mathrm{eq}}(\mathrm{t})$. Finally, the equilibrium runoff coefficient $\mathrm{C}_{\mathrm{eq}}$ is obtained using a dynamic version of the Schreiber's equation:

$$
C_{e q}(t)=P(t) \cdot e^{-a \cdot \widehat{\psi}(t ; \alpha)}
$$

The variable $\hat{\psi}$ is the dynamic aridity ratio, which results from dividing the smoothed $P E T$ and $P$ series (variables with superindex $\wedge$ in the formulas represent the original variable transformed by an exponential smoothing operator with parameter $\alpha$ ):

$$
\hat{\psi}(t ; \alpha)=\frac{\widehat{P E T}(t ; \alpha)}{\widehat{P}(t ; \alpha)}
$$

Physically, the model reflects that the discharge growth is directly proportionally to the level of existing discharge and to the margin that remains until reaching its saturation discharge, while it is inversely proportional to $\mathrm{C}_{\mathrm{eq}}$, a proxy of the wetness conditions of the soil $\left(\mathrm{C}_{\mathrm{eq}}=0\right.$ for totally dry and $\mathrm{C}_{\mathrm{eq}}=1$ for fully saturated).

The resulting model has four parameters: $a, \tau, k$ and $\alpha$. Parameter $a$ (adim.) determines the shape of the equilibrium function which yields the equilibrium runoff coefficient in Schreiber's equation (Eq. 2). Parameter $\tau$ (days) is al routing lag, and $k\left(\mathrm{~mm}^{-1}\right)$ is the and $\alpha$ due to the way in which equilibrium is pursued, that is, due to the growth equation). Parameter $k\left(\mathrm{~mm}^{-1}\right)$ represents the growth rate and its inverse is equivalent to a representative soil thickness. Finally, parameter $\alpha$ (days ${ }^{-1}$ ) is the length of the exponential smoothing filter, which represents a longterm characteristic response time of the watershed (parameter $\tau$ is the other, short-term response time).

Assuming that during each timestep $P(t)$ and its derived variables are constant, the logistic equation (Eq. 1) has analytical solution, providing an explicit and unconditionally stable numerical scheme to solve it:

$$
Q_{t}=\frac{Q_{t-1} \cdot Q_{e q, t-\tau}}{Q_{t-1}+\left(Q_{e q, t-\tau}-Q_{t-1}\right) \cdot \exp \left(-k \cdot \Delta t \cdot P_{t-\tau}\right)},
$$

$$
Q_{t}=\frac{Q_{t-1} \cdot C_{e q, t-\tau}}{C_{e q, t-\tau}+k \cdot Q_{t-1} \cdot \Delta t}, \quad Q_{e q, t-\tau}=0
$$

The lagged variable $P_{t-\tau}$ (that is also used to obtain $\left.Q_{e q, t-\tau}\right)$ and $C_{e q, t-\tau}$ ) can be expressed as a linear combination of their last discrete values, assuming that the lag parameter $\tau$ is less than the time increment $\Delta t$, in this case 1 day:

$$
P_{t-\tau}=\left(1-\frac{\tau}{\Delta t}\right) \cdot P_{t}+\frac{\tau}{\Delta t} \cdot P_{t-1}, 0 \leq \tau \leq \Delta t
$$

where:

$$
\begin{gathered}
C_{e q, t}=\exp \left(-a \cdot \hat{\psi}_{t}(\alpha)\right) \\
Q_{e q, t}=P_{t} \cdot C_{e q, t}
\end{gathered}
$$

The dynamic aridity ratio $\hat{\psi}_{t}(\alpha)$ can be easily obtained using the exponential smoothing recursive algorithm:

$$
\begin{gathered}
\hat{\psi}_{t}(\alpha)=\frac{\widehat{P E}_{t}(\alpha)}{\widehat{P}_{t}(\alpha)} \\
\widehat{P E}_{t}(\alpha)=\alpha \cdot P E_{t}+(1-\alpha) \cdot \widehat{P E}_{t-1} \\
\hat{P}_{t}(\alpha)=\alpha \cdot P_{t}+(1-\alpha) \cdot \widehat{P}_{t-1}
\end{gathered}
$$

While this is the general formulation of the model, it must be noted that the $\tau$ used to obtain $q_{L}$ is one order of magnitude lower than the travel times of flood waves in the main river. Therefore, it is not relevant to keep this parameter as a degree of freedom of the model, because it is mostly damped by the diffusion process and poses a problem of identifiability during model calibration. On these bases, the proposed version of the LEM sub-model to be plugged into the LEM-DIF model will include only three parameters: $a, k$ and $\alpha$.

\subsection{Diffusive Wave Model (DIF)}

The second part of the model solves the discharge evolution $Q(x, t)$ along the main axis, using the analytical solution of the Hayami equation with lateral flow obtained by Moussa (1996), which is derived by applying some hypotheses to the diffusive wave equation:

$$
\frac{\partial Q}{\partial t}+C\left(\frac{\partial Q}{\partial x}-q_{L}(t)\right)-D\left(\frac{\partial^{2} Q}{\partial x^{2}}-\frac{\partial q_{L}(t)}{\partial x}\right)=0
$$

$Q(x, t)$ is the flow in the main channel, $q_{L}(t)$ is the lateral flow and $C, D$ are the two parameters of the diffusive model, the celerity $(\mathrm{m} / \mathrm{s})$ and diffusivity $\left(\mathrm{m}^{2} / \mathrm{s}\right)$, respectively. As in any differential equation, the initial conditions and the boundary conditions must be specified for $Q$ and $q_{L}$.

Assuming that $C$ and $D$ are constant, the analytical solution of this equation provides an explicit numerical scheme, which is computationally efficient and with a high 
degree of numerical stability (but not unconditionally stable, as will be seen later).

The hypotheses involved and the complete solution can be found in the original article by Moussa (1996). The final expressions used in the LEM-DIF model are as follows:

$$
\phi(t)=\frac{C}{L} \int_{0}^{t}\left[Q_{a}(\lambda)-Q_{a}(0)\right] d \lambda
$$

where

$$
Q_{a}(t)=L \cdot q_{L}(t)
$$

$K(t)$ is the Hayami kernel function defined as:

$$
K_{\theta, z}(t)=\left(\frac{\theta z}{\pi}\right)^{1 / 2} \frac{\exp ^{\left[z\left(2-\frac{\theta}{t}-\frac{t}{\theta}\right)\right]}}{t^{3 / 2}}
$$

with

$$
\begin{gathered}
\theta=\frac{L}{C} ; \quad z=\frac{C \cdot L}{4 D} \\
O(t)=\phi(t)+[I(t)-\phi(t)] * K(t)
\end{gathered}
$$

Where $I(t)$ and $O(t)$ are, respectively, the upstream $(x=0)$ inflow minus the baseflow and the downstream $(x=L)$ outflow minus the baseflow.

\subsection{Logistic Equilibrium Model with Diffusive Wave (LEM-DIF)}

Assuming that the routing of the lateral basins is given by a constant lag proportional to the mean time of concentration ( $\tau$ constant), and that the magnitudes of length $(L)$, width $(W)$ and sinuosity of the main river $(S)$ are determined by geographic (i.e. orthophotos) analysis, the final LEM-DIF model used in this application case consists of 5 parameters for each element considered:

- $\quad A, k, \alpha$ of the LEM sub-model. These parameters reflect the watershed behaviour, including in an aggregate way all the tributary basins.

- $\quad C$ and $D$ of the DIF sub-model. These parameters reflect the geometric and hydraulic characteristics of the main river (average slope, roughness and average width).

The numerical implementation of LEM-DIF model has been carried out in the Matlab environment. Model calibration can be done manually (trial-error) or automatically. In this application we have applied an automatic (supervised) calibration algorithm that performs a global search in a hypercube of the parameter space, and then applies a local search algorithm (fmincon from Matlab), in each exploration region. The objective function to be minimized, in this case, will be 1-NS, where NS is the Nash-Sutcliffe coefficient, a widely used measure of goodness-of-fit in hydrological modeling ranging from $-\infty$ to 1 (where 1 is the perfect fit and 0 the fit derived from approximating a series with its constant mean value).

\section{Application case: the Tebicuary River Basin in Paraguay}

\subsection{General description of the basin}

The Tebicuary River Basin is located at the departments of Paraguarí, Itapúa, Caaguazú, Guairá, Caazapá, Ñeembucú, Misiones and Cordillera: it is the largest hydrographic basin in the eastern region of Paraguay (Figure 2).

The basin area is approximately $28,423 \mathrm{~km}^{2}$ (equivalent to the $6.5 \%$ of the country and the $16.5 \%$ of the eastern region area). The length of its main course is approximately $500 \mathrm{~km}$ and ends at the Paraguay River at km 147 (counting from the Paraguay-Paraná confluence), about $40 \mathrm{~km}$ upstream from Puerto de Pilar.

The most important tributaries on its right bank are the rivers Tebicuary-Mi, Pirapó, Negro and the streams Cabacuá and Mbuyapey; while on its left bank it is fed by the streams Aguaray, San Roque, Gueyracay and Tajy, among others.

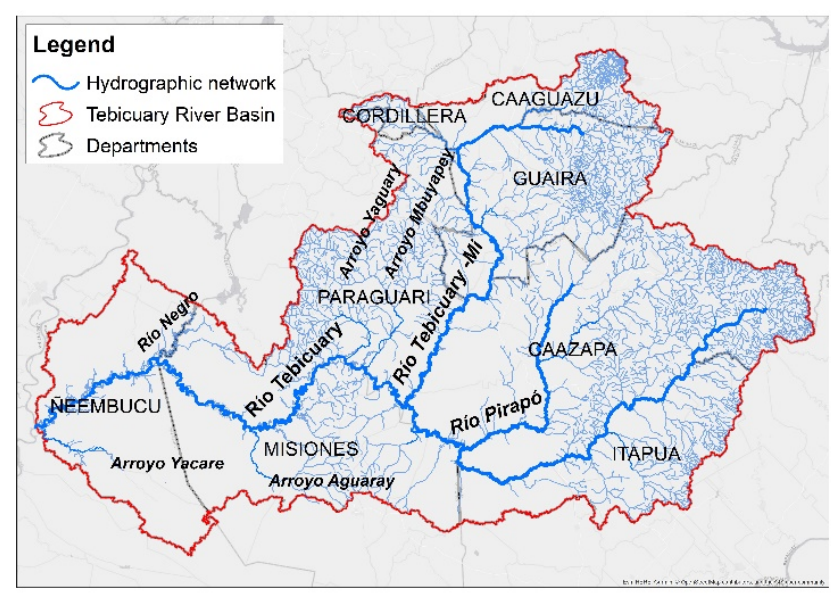

Figure 2. Location of the Tebicuary River Basin and its hydrographic network.

The Tebicuary River Basin has some characteristic features, particulary the low topographic slopes and a high sinuosity of the main river courses, which affect the propagation of hydrographs.

On a daily scale, the discharge evolution in the middle and low points is dominated by diffusive processes of wave propagation, more than by conventional hydrological processes, which are hardly recognizable. In Villa Florida, the only station with sufficient data to perform a formal calibration, there are approximately 12 days of lag between the peak values of average precipitation in the basin and the peak of the flow, as can be seen in Figure 3; other sub-basins are expected to experience a similar phenomenon, although with different lags. Taking into account that the order of magnitude of 
the distance that the flow must travel from the center of gravity of the basin to Villa Florida is about $200 \mathrm{~km}$ (100 $\mathrm{km}$ in a straight line, which approximately double due to the channel sinuosity), the average speed of propagation of the hydrographs is $16.7 \mathrm{~km} /$ day $(0.19 \mathrm{~m} / \mathrm{s}$ or $0.69 \mathrm{~km} / \mathrm{h})$.

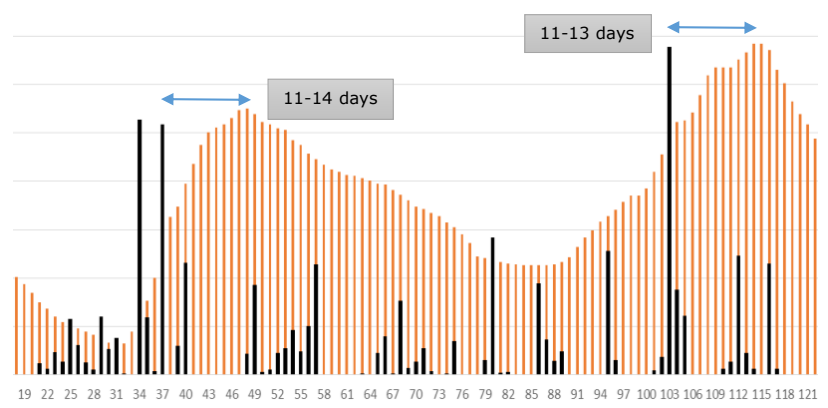

Figure 3. Evolution of the mean precipitation in the basin (black bars) and the discharges (orange bars) in Villa Florida during a period of 100 days. The vertical scale is different for both signals, in order to highlight the time lag.

\subsection{Definition and characterization of sub-basins}

The definition of the sub-basins has been made from the hydrographic network and available topography, Digital Terrain Models (DTM) from global databases (DTM from the ASTER database with a resolution of 30 $\mathrm{m}$, published within a joint initiative of NASA and METIJapan in October 2011, and DTM from the ALOS Mission with a resolution of $12.5 \mathrm{~m}$, carried out by JAXA -Japan in collaboration with NASA). This information has been imported into the Arc-Swat package, which has algorithms for defining sub-basins. Taking into account the available information and practical goals, it has been considered appropriate to divide the Tebicuary River Basin into nine sub-basins, as shown in Figure 4.

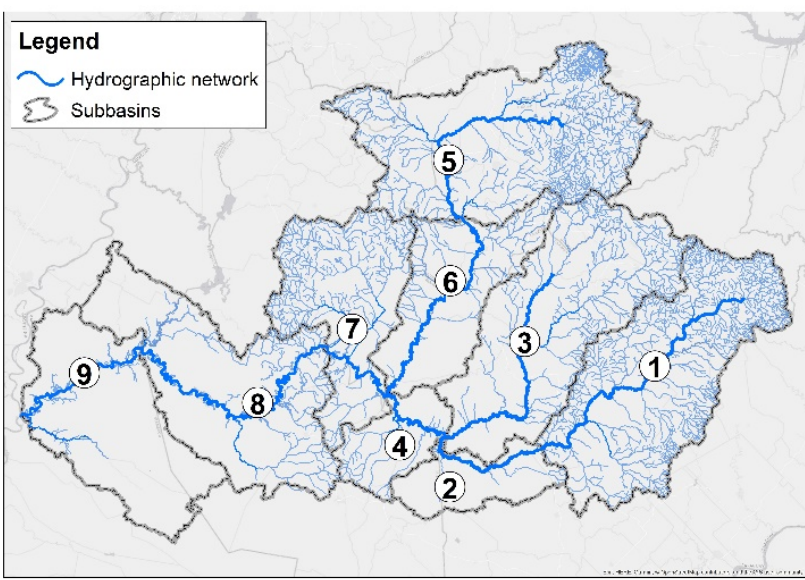

Figure 4. Sub-basins considered for the modelling within the Tebicuary River Basin.

Reducing this number further would have meant creating very large management units, with very different uses and flow regimes, while increasing it means multiplying the complexity of the models without necessarily expanding the information it contains, limited by the quantity and quality of the available data.

The main characteristics of the sub-basins generated are shown in Tables 2 and 3. The numbers correspond to the following hydro-toponymy (Table 1):

\begin{tabular}{|c|c|}
\hline Sub-basin & Name \\
\hline 1 & Alto Tebicuary I (untill Yuty approx.) \\
\hline 2 & Alto Tebicuary II (untill confluence to Pirapó) \\
\hline 3 & Pirapó Basin \\
\hline 4 & Medio Tebicuary I \\
\hline 5 & Alto Tebicuary Mi (untill Iturbe approx.) \\
\hline 6 & Bajo Tebicuary Mi \\
\hline 7 & Medio Tebicuary II (until Villa Florida) \\
\hline 8 & Bajo Tebicuary I \\
\hline 9 & Bajo Tebicuary II \\
\hline
\end{tabular}

Table 1. Hydrotoponymy used at each sub-basin.

The sub-basins considered range between 1,000 and $5,000 \mathrm{~km}^{2}$, although the main ones, considering the numbers 2 and 4 as transition units, have around 4,000 $\mathrm{km}^{2}$. Possibly the most characteristic feature of the basin as a whole $\left(28,423 \mathrm{~km}^{2}\right)$ is the high sinuosity, which has an average value of 2.1 and reaches 2.73 in sub-basin No. 6 , the lower Tebicuary Mi. The slopes are also extremely low, becoming almost negligible in the final section of the Alto Tebicuary (SB-6), before the confluence with the Pirapó (which is also the lowest-sloping sub-basin). The average widths of the channel have been obtained by averaging values in a dozen representative points of each section, from the aerial photos, and should be taken as an estimate. The length of the valley is a parameter whose magnitude can also vary depending on the calculation criteria, and which in this case has been obtained by dividing the length of the main channel by the sinuosity; the average width is derived from dividing the area by the length. These two representative dimensions will be important for the hydrological modeling.

\begin{tabular}{|c|c|c|c|c|}
\hline Sub-basin & $\begin{array}{c}\text { Average } \\
\text { width (m) }\end{array}$ & $\begin{array}{c}\text { Average } \\
\text { slope (\%) }\end{array}$ & $\begin{array}{c}\text { Length } \\
\text { (km) }\end{array}$ & $\begin{array}{c}\text { Sinuosity } \\
\text { (dimless.) }\end{array}$ \\
\hline 1 & 25 & 0.034 & 249.3 & 2.09 \\
\hline 2 & 60 & 0.001 & 103.7 & 2.14 \\
\hline 3 & 30 & 0.029 & 204.7 & 2.25 \\
\hline 4 & 80 & 0.046 & 65.6 & 2.09 \\
\hline 5 & 35 & 0.031 & 164.3 & 1.82 \\
\hline 6 & 65 & 0.016 & 176.1 & 2.73 \\
\hline 7 & 150 & 0.052 & 57.8 & 1.71 \\
\hline 8 & 155 & 0.056 & 186.8 & 1.95 \\
\hline 9 & 220 & 0.070 & 88.6 & 1.50 \\
\hline
\end{tabular}

Table 2. Characteristics of the main river of each sub-basin. 


\begin{tabular}{|c|c|c|c|c|}
\hline Sub-basin & $\begin{array}{c}\text { Sub-basin } \\
\text { area } \\
\mathbf{( k m}^{2} \mathbf{)}\end{array}$ & $\begin{array}{c}\text { Valley } \\
\text { length } \\
\mathbf{( k m )}\end{array}$ & $\begin{array}{c}\text { Total } \\
\text { drainage } \\
\text { area } \\
\mathbf{( k m}^{\mathbf{2}} \mathbf{)}\end{array}$ & $\begin{array}{c}\text { Average } \\
\text { valley } \\
\text { width } \\
\mathbf{( k m )}\end{array}$ \\
\hline 1 & 4410.8 & 119.4 & 4410.8 & 36.9 \\
\hline 2 & 1104.2 & 48.5 & 5515.0 & 22.8 \\
\hline 3 & 3957.3 & 91.1 & 3957.3 & 43.5 \\
\hline 4 & 1014.2 & 31.5 & 10486.5 & 32.2 \\
\hline 5 & 4814.9 & 90.4 & 4814.9 & 53.2 \\
\hline 6 & 2351.5 & 64.6 & 7166.4 & 36.4 \\
\hline 7 & 2727.0 & 33.9 & 20379.9 & 80.5 \\
\hline 8 & 4086.2 & 95.9 & 24466.1 & 42.6 \\
\hline 9 & 3957.3 & 59.0 & 28423.4 & 67.0 \\
\hline
\end{tabular}

Table 3. Main shape characteristics of each sub-basin.

\subsection{Hydro-meteorological information}

Regarding hydrological data, the Villa Florida gauge station located in the middle-lower river basin has been selected for model calibration, as it is the only station in the basin with more than five years of data. This station contains daily flow data for two historical periods: 19742002 and 2013-2017.

Instrumental rainfall data is available from seven meteorological stations within the Tebicuary River Basin. These data have relatively good quality, as well as good temporal resolution (1 day); however, there is a lack of spatial coverage within the basin and the series, although long in some cases, do not always overlap. Given this lack of instrumental data, the series of the Tropical Rainfall Measurement Mission (TRMM) database (1998-2014), which have a spatial resolution of $0.25^{\circ}$ (approximately 25 $\mathrm{km}$ ) and temporal of 3 hours, have been used to complement the pluviometers. TRMM data come from calibrating several remote sensors mounted on a satellite in non-polar orbit (including a microwave precipitation radar), jointly funded by NASA (USA) and JAXA (its Japanese equivalent). The TRMM database is freely available and can be downloaded at: https://trmm.gsfc.nasa.gov/.

To obtain the precipitation series for each sub-basin, the TRMM project data (140 points selected around the study area) have been calibrated using the instrumental data of the 7 meteorological stations and have been averaged for each sub-basin. For its calibration, two corrections have been made, one in time (the TRMM signal has been advanced 1 day) and one in magnitude (using monthly correction factors).

With regard to the potential evapotranspiration data (PET), monthly series have been downloaded from the CRU TS4.01 database of the University of East Anglia Climatic Research Unit (Harris, I.C. and Jones, P.D., 2017) in the study area, with a spatial resolution of $0.5^{\circ}$ in the period 1998-2014. Although the series covers a period of more than 100 years, only the information for the period 1998-2014 has been extracted, which is the period used for hydrological simulations. Subsequently, the monthly data have been downscaled to daily values, assuming a constant value for each month. These data are freely available and can be downloaded at: http://www.cru.uea.ac.uk/.

Figure 5 presents the location of the Villa Florida discharge gauge and the seven meteorological stations used for the TRMM calibration.

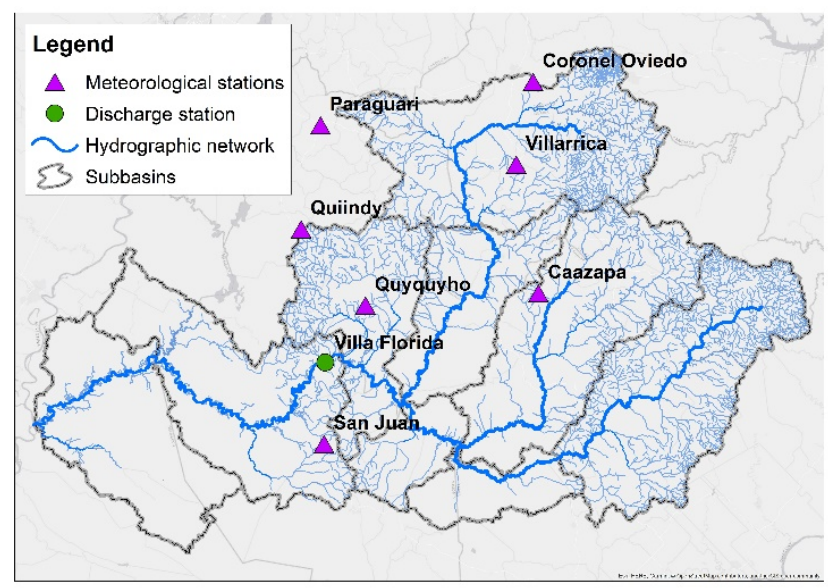

Figure 5. Location of the Villa Florida discharge gauge and the seven meteorological stations within the Tebicuary River Basin.

Combining these PET data with the average precipitation data, we can obtain the mean aridity index $(E T P / P)$ by sub-basins.

Table 4 presents the values of the annual mean precipitation, the annual mean PET as well as the aridity index $(A I)$ obtained for each sub-basin.

\begin{tabular}{|c|c|c|c|}
\hline Sub-basin & $\boldsymbol{P}(\mathbf{m m})$ & $\boldsymbol{P E T}(\mathbf{m m})$ & $\boldsymbol{A I}(\boldsymbol{P E T} / \boldsymbol{P})$ \\
\hline 1 & 1641 & 1616 & 0.97 \\
\hline 2 & 1620 & 1549 & 0.94 \\
\hline 3 & 1580 & 1582 & 0.98 \\
\hline 4 & 1613 & 1526 & 0.97 \\
\hline 5 & 1598 & 1564 & 0.97 \\
\hline 6 & 1552 & 1546 & 0.97 \\
\hline 7 & 1499 & 1527 & 0.98 \\
\hline 8 & 1469 & 1542 & 1.03 \\
\hline 9 & 1577 & 1531 & 1.04 \\
\hline Average & $\mathbf{1 6 4 1}$ & $\mathbf{1 5 6 0}$ & $\mathbf{0 . 9 9}$ \\
\hline
\end{tabular}

Table 4. Annual average precipitation $(P)$, annual average potential evapotranspiration $(P E T)$ and aridity index $(A I)$ of each sub-basins considered.

The average annual precipitation is $1577 \mathrm{~mm}$ in the Tebicuary River Basin. By sub-basin, the results show a decrease in the average precipitation from the southeast of the basin to the west-northwest.

The annual average of the PET is about $1560 \mathrm{~mm}$, and presents a small variation between years. The months where the atmosphere presents a greater capacity to extract energy from the system are around the change of year, between November and March, when PET is three times 
higher on average than in the colder months, from May to August.

\subsection{Model calibration}

The methodology followed in this article to check the efficiency of the LEM-DIF model starts with the calibration and validation of the model with the discharge data. Afterwards, the results will be compared with the Muskingum routing model, in order to draw some final conclusions.

Calibrating a hydrological model is a complex process, especially for large basins. The difficulty in finding a single set of parameters that responds to the behavior of a complex basin has been extensively studied in the literature (Vrugt et al., 2003) and has been attributed to various uncertainties inherent in both the models and real systems (Moradkhani et al., 2005). Regarding the issue of calibration and uncertainty analysis, there are several different approaches ranging from manual calibration to the use of automatic optimization algorithms (Beven, 2002).

For conceptual models with few parameters, automatic calibration is usually the most appropriate, since the danger of equifinality decreases with decreasing number of parameters. This method has been used for the calibration of the LEM-DIF hydrological model.

Specifically, the calibration of the model has been carried out considering uniform model parameters for the seven sub-basins upstream of Villa Florida (see Figure 4), the only point in the river network where there is a long series of daily measured flows. There is overlap between the TRMM precipitation data with the flow data at that point, only in two time periods: Period 1) 1998-2001 (4 years) and period 2) 2013-2014 (2 years).

To calibrate the model parameters, more weight has been given to the data from period 1 , as it is longer and it is expected that there will be fewer changes in the natural regime. The calibration has been carried out combining a mathematical optimization procedure, with a final manual adjustment of the parameters. The optimization has been carried out with a variant of the "fmincon" algorithm included in the Matlab numerical package, using the objective function to minimize Fobj = 1- NSE, where NSE is the Nash-Sutcliffe efficiency coefficient. Threshold values to indicate a model of sufficient quality have been suggested between $0.5<\mathrm{NSE}<0.65$ (Ritter et al., 2003; Moriasi et al., 2007).

The same function applied to the logarithm of the flow rates (NSEL) has also been minimized, which causes that the high values do not have as much weight in the calibration.

Furthermore, the volume error or percentage of bias (PBIAS, Eq. 19), that measures the average tendency of the simulated data to be larger or smaller than their observed counterparts (Gupta et al., 1999) has also been obtained. The optimal value of PBIAS is 0 , with low magnitude values indicating an accurate model simulation. This indicator is highly influenced by high flow rates.

$$
N S E=\frac{\sum_{t=1}^{n}\left(Q_{m, t}-Q_{o, t}\right)^{2}}{\sum_{t=1}^{n}\left(Q_{o, t}-\overline{Q_{o}}\right)^{2}}
$$

$$
P B I A S=\left[\frac{\sum_{t=1}^{n}\left(Q_{o, t}-Q_{m, t}\right) * 100}{\sum_{t=1}^{n}\left(Q_{o, t}\right)}\right]
$$

where $\overline{Q_{o}}$ is the mean of the observed discharges, $Q_{o, t}$ is observed discharge at time $\mathrm{t}, Q_{m, t}$ is modeled discharge at time t.

The best-fit parameters obtained for both periods and

\begin{tabular}{|c|c|c|c|c|c|}
\hline \multirow{2}{*}{\multicolumn{2}{|c|}{$\begin{array}{l}\text { Period } \\
\text { Objective } \\
\text { Function }\end{array}$}} & \multicolumn{2}{|c|}{1 (1998-2002) } & \multicolumn{2}{|c|}{$2(2013-2014)$} \\
\hline & & \multirow{2}{*}{$\begin{array}{c}\text { NSE } \\
0.27\end{array}$} & \multirow{2}{*}{$\begin{array}{c}\text { NSEL } \\
0.26\end{array}$} & \multirow{2}{*}{$\begin{array}{c}\text { NSE } \\
0.21\end{array}$} & \multirow{2}{*}{$\begin{array}{c}\text { NSEL } \\
0.18\end{array}$} \\
\hline \multirow{5}{*}{ 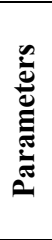 } & $A$ & & & & \\
\hline & $k$ & 0.012 & 0.019 & 0.015 & 0.021 \\
\hline & $\alpha$ & 0.023 & 0.013 & 0.027 & 0.029 \\
\hline & $C$ & 18.60 & 16.97 & 20.14 & 18.27 \\
\hline & $D$ & 50.01 & 68.29 & 64.49 & 262.28 \\
\hline \multirow{3}{*}{$\underset{Z}{*}$} & NSE & 0.81 & 0.75 & 0.91 & 0.89 \\
\hline & NSEL & 0.73 & 0.78 & 0.86 & 0.89 \\
\hline & PBIAS & $-0.92 \%$ & $-4.74 \%$ & $0.78 \%$ & $-3.52 \%$ \\
\hline
\end{tabular}
objective functions, are presented in Table 5.

Table 5. Optimal parameters and goodness of fit for the two calibration periods. LEM-DIF model.

The degree of fit is good for the two objective functions used, giving better results by optimizing the NSE, with an almost negligible PBIAS.

Based on these results, the final values have been determined for the model parameters (Table 6), giving more weight to the results of period 1 . Using this single set of parameters, the final NSE values for period 1 and 2 are 0.8 and 0.87 , respectively. Figures 6 and 7 show the measured and simulated series in the two periods.

\begin{tabular}{|c|c|}
\hline Parameter & Value \\
\hline $\boldsymbol{A}$ & 0.25 \\
\hline $\boldsymbol{k}$ & 0.013 \\
\hline $\boldsymbol{\alpha}$ & 0.024 \\
\hline $\boldsymbol{C}$ & 19.22 \\
\hline $\boldsymbol{D}$ & 55.80 \\
\hline
\end{tabular}

Table 6. Final calibrated values of the model parameters. 


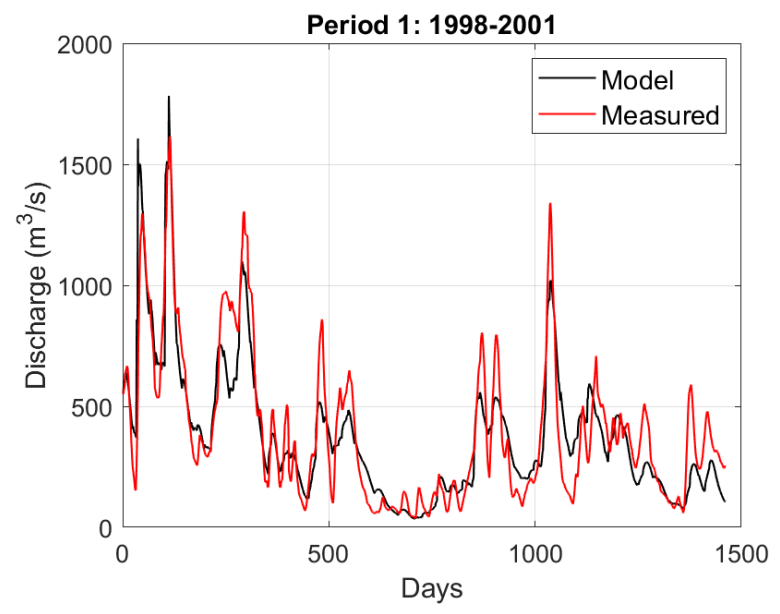

Figure 6. Measured and simulated discharges using the LEMDIF model. Period 1 (1998-2001).

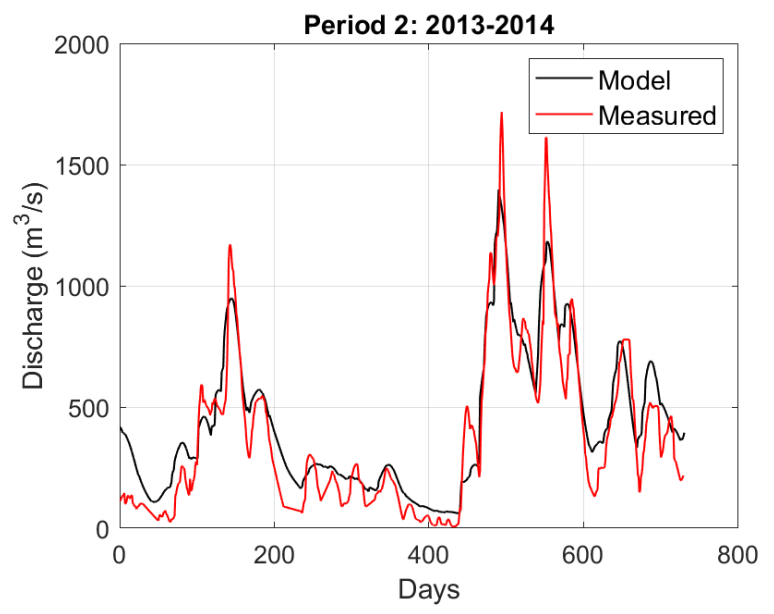

Figure 7. Measured and simulated discharges using the LEMDIF model. Period 2 (2013-2014).

\subsection{Comparison with Muskingum method}

This section compares the goodness of fit achieved by the LEM-DIF model with that obtained from the application of the LEM hydrological model coupled with the Muskingum routing model.

The Muskingum method is a commonly used hydrologic routing method based on a variable dischargestorage relationship. This method models the storage volume of flooding in a river channel by a combination of wedge and prism storages (Figure 8) using a simple finite difference approximation of the continuity equation:

$$
I-Q=\frac{\Delta S}{\Delta t}
$$

where $I=$ average upstream flow (inflow to reach) during a period $\Delta t ; Q=$ average downstream flow (outflow from reach) during the same period; $\Delta S=$ change in the storage in the reach during the period.

Discretizing in the space $(x, t)$ we obtain:

$$
\left(\frac{I_{t-1}+I_{t}}{2}\right)-\left(\frac{Q_{t-1}+Q_{t}}{2}\right)=\left(\frac{S_{t}+S_{t-1}}{\Delta t}\right)
$$

where the inflow values at the beginning and the end of the time interval are $I_{t}$ and $I_{t+1}$, respectively, the corresponding values of the outflow are $Q_{t}$ and $Q_{t+1}$ and $S_{t}$ and $S_{t+1}$ the storage volumes for both instants.

Therefore, the Muskingum method establishes a relationship between the volume stored with the inflow and the outflow and also establishes that this relationship is a linear proportion.

During the advance of a flood wave, inflow exceeds outflow, producing a wedge of storage. During the recession, outflow exceeds inflow, resulting in a negative wedge. In addition there is a prism of storage which is formed by a volume of constant cross section along the length of prismatic channel (Chow et al., 1988).

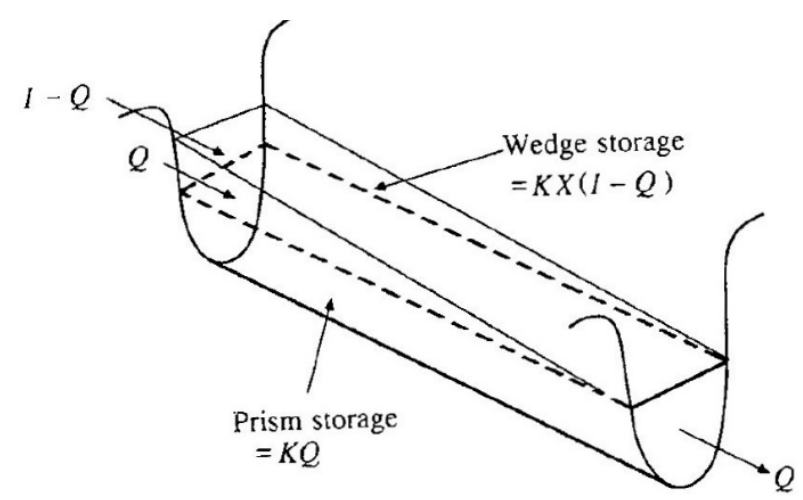

Figure 8. Prism and wedge storage in a channel reach. Source: Chow et al. (1988).

Assuming that the cross-sectional area of the flood flow is directly proportional to the discharge at the section, the volume of prism storage is equal to $K Q$ where $K$ is a proportionality coefficient, and the volume of wedge storage is equal to $K X(I-Q)$, where $X$ is a weighting factor having the range $0 \leq X \leq 0.5$. The total storage is therefore the sum of two components:

$$
S=K \cdot Q+K \cdot X(I-Q)=K[X \cdot I+(1-X) Q]
$$

The value of $X$ depends on the shape of the wedge storage. The value of $X$ ranges from 0 for reservoir-type storage to 0.5 for a full wedge. When $X=0$, there is no wedge and hence no backwate; this is the case of a level pool reservoir, $S=K Q$. In natural streams, $X$ is between 0 and 0.3 with the mean value nera 0.2 . The parameter $K$ is the time of travel of the flood wave throug the channel reach.

The values of storage at a time $t$ and $t+1$ can be written, respectively, as:

$$
S_{t}=K\left[X I_{t}+(1-X) Q_{t}\right]
$$

and

$$
S_{t+1}=K\left[X I_{t+1}+(1-X) Q_{t+1}\right]
$$

Using Eqs. 23 and 24, the change in storage over a time interval $\Delta t$ is: 


$$
\begin{array}{r}
S_{t+1}-S_{t}=K\left[X I_{t+1}+(1-X) Q_{t+1}\right] \\
-K\left[X I_{t}+(1-X) Q_{t}\right]
\end{array}
$$
21 as:

The change in storage can also be expressed using Eq.

$$
S_{t+1}-S_{t}=\frac{\left(I_{t}+I_{t+1}\right)}{2} \Delta t-\frac{\left(Q_{t}+Q_{t+1}\right)}{2} \Delta t
$$

combining Eqs. 25 and 26 and simplifying gives:

$$
Q_{t+1}=C_{1} I_{t+1}+C_{2} I_{t}+C_{3} I Q_{t}
$$

which is the routing equation for the Muskingum method where:

$$
\begin{aligned}
C_{1} & =\frac{\Delta t-2 K X}{2 K(1-X)+\Delta t} \\
C_{2} & =\frac{\Delta t+2 K X}{2 K(1-X)+\Delta t} \\
C_{3} & =\frac{2 K(1-X)-\Delta t}{2 K(1-X)+\Delta t}
\end{aligned}
$$

Note that $C 1+C 2+C 3=1$.

If observed inflow and outflow hydrographs are available for a river reach the values $K$ and $X$ can be determined.

In this case, since flow data are available at a single station (Villa Florida) this is not possible and what is proposed is the realization of an automatic calibration keeping the same parameters of the LEM hydrological model and only calibrating those corresponding to the Muskingum model ( $\mathrm{K}$ and $\mathrm{X}$ ) and considering uniform model parameters for the seven sub-basins upstream the discharge station, as for the LEM-DIF model.

In this way, it will be possible to evaluate the adequacy

\begin{tabular}{|c|c|c|c|c|c|}
\hline \multirow{2}{*}{\multicolumn{2}{|c|}{$\begin{array}{c}\text { Period } \\
\text { Objective } \\
\text { Function }\end{array}$}} & \multicolumn{2}{|c|}{1 (1997-2002) } & \multicolumn{2}{|c|}{$2(2013-2014)$} \\
\hline & & \multirow{2}{*}{$\begin{array}{l}\text { NSE } \\
0.25\end{array}$} & \multirow{2}{*}{$\frac{\text { NSEL }}{0.25}$} & \multirow{2}{*}{$\begin{array}{l}\text { NSE } \\
0.25\end{array}$} & \multirow{2}{*}{$\begin{array}{c}\text { NSEL } \\
0.25\end{array}$} \\
\hline \multirow{5}{*}{ 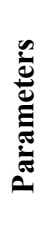 } & $A$ & & & & \\
\hline & $\boldsymbol{k}$ & 0.013 & 0.013 & 0.013 & 0.013 \\
\hline & $\alpha$ & 0.024 & 0.024 & 0.024 & 0.024 \\
\hline & $K$ & 2.91 & 2.15 & 2.69 & 1.78 \\
\hline & $X$ & 0.00 & 0.05 & 0.09 & 0.08 \\
\hline \multirow{3}{*}{ 江 } & NSE & 0.82 & 0.80 & 0.89 & 0.85 \\
\hline & NSEL & 0.71 & 0.71 & 0.74 & 0.75 \\
\hline & PBIAS & $-9.45 \%$ & $-9.50 \%$ & $13.67 \%$ & $13.76 \%$ \\
\hline
\end{tabular}
of using the diffusive wave equation of the DIF sub-model instead of the Muskingum model.

After conducting the mathematical optimization, the parameters obtained, for both periods and objective functions, using the Muskingum routing model are presented in Table 7:

Table 7. Optimal parameters and goodness of fit for the two calibration periods. LEM+Muskingum model.
The best-fit parameters and the goodness-of-fit obtained is very similar for the two periods and the two objective functions and very similar to those obtained with the LEM-DIF model, except for the value of the PBIAS (volume deviation) that is much greater. The new model performs somewhat better in this particular application, although the LEM-Muskingum model also yields a good result.

The final parameter values have been determined, as for the LEM -DIF model, giving more weight to the results of period 1 (Table 8 ). The final NSE coefficient is 0.80 for period 1 , and 0.87 for period 2 .

\begin{tabular}{|c|c|}
\hline Parameter & Value \\
\hline $\boldsymbol{A}$ & 0.25 \\
\hline $\boldsymbol{k}$ & 0.013 \\
\hline $\boldsymbol{\alpha}$ & 0.024 \\
\hline $\boldsymbol{K}$ & 2.45 \\
\hline $\boldsymbol{X}$ & 0.04 \\
\hline
\end{tabular}

Table 8. Final calibrated values of the model parameters using the Muskingum routing model.

\section{Conclusions}

The LEM-DIF model is based on the combination of two simple conceptual sub-models, one for hydrology and one for hydraulics, and is capable of representing the discharges of large river basins with significant wave propagation effects in a lumped and efficient way, using a limited number of parameters (5). The model rests on the assumption that a large river basin can be represented as a rectangular region with a certain width-to-length ratio; the main river flows along the length of the rectangle and all the tributaries amount to a lateral uniform flow per unit width. The lateral inflows are represented by the Logistic Equilibrium Model, while the flow evolution along the main river is given by the analytical solution to the Hayami equation with a uniform lateral inflow, as presented by Moussa (1996). It is assumed that the lateral inflows are incorporated into the main river without significant propagation effects in the reach so that routing can be carried out with conventional methods and all the propagation effects occur along the main river.

The Tebicuary River Basin in Paraguay has been chosen as application case, due to its low slope and high sinuosity which yield strong flood propagation effects. On a daily scale, the discharge evolution in the mid and low points of the basin is dominated by diffusive processes of wave propagation, The LEM-DIF model has been applied to the Tebicuary River at Villa Florida $\left(20,400 \mathrm{~km}^{2}\right)$ relying on mean daily precipitations and potential evapotranspiration as input data. The results have been compared with the Muskingum routing model.

The calibration has been carried out by combining a mathematical optimization procedure with a final manual adjustment of the parameters, over two evaluation periods. The optimization has been carried out with a global optimization algorithm in Matlab, using the Nash-Sutcliffe Efficiency (NSE) coefficient and its logarithmic version 
(NSEL) as objective functions; the volume error or percentage of bias (PBIAS) has also been obtained but not used for calibration.

The LEM-DIF model provides a satisfactory fit to the measured data, given the large basin area and the uncertainties in all the variables involved. The same hydrologic sub-model (LEM) combined with the Muskingum routing method provides similar results in terms of NSE and NSEL, but a significantly higher volume bias. The LEM-DIF model is computationally efficient, relatively easy to calibrate and is available at a daily scale in Matlab version. It must be noted that the application of the model in smaller river basins or with milder propagation effects would probably require a lower (hourly) timestep, and would entail a lengthier calibration process.

\section{References}

1. Allasia DG, Collischonn W, Silva BC, Tucci CEM. (2006). Large basin simulation experience in South America. In: Predictions in Ungauged Basins: Promise and Progress. Proceedings of Symposium S7 held during the Seventh IAHS Scientific Assembly at Foz do Iguaçu, Brazil, April 2005. IAHS Publication 303, pp. 360-370.

2. Beven, K. J. (2002). Towards a coherent philosophy for modeling the environment. Proceedings of the Royal Society of London. Vol. 458, Issue 2026, $2465-$ 2484.

3. Chow, V. T., Maidment, D. R., \& Larry, W. (1988). Mays. Applied hydrology. McGraw-Hill Book Company.

4. Collischonn W, Allasia DG, Silva BC, Tucci CEM. (2007). The MGB-IPH model for large-scale rainfallrunoff modeling. Hydrological Sciences Journal 52: 878-895.

5. Gupta, H.V.; Sorooshian, S.; Yapo, P.O. (1999). Status of automatic calibration for hydrologic models: Comparison with multilevel expert calibration. $J$. Hydrol. Eng. 4, 135-143.

6. IHCantabira (2019). Metodología para la determinación y evaluación de caudales ecológicos y planes de manejo de cuencas en Paraguay Aplicación a la cuenca piloto del río Tebicuary. CTCN, UNIDO.

7. Malthus, T. R. (1798). An Essay on the Principle of Population. Printed for J. Johnson, London.

8. Moradkhani, H., Sorooshian, S., Gupta, H., Houser, P. (2005). Dual state-parameter estimation of hydrological models using ensemble Kalman filter. Advances in Water Resources 28: 135-147.

9. Moriasi, D. N.; Arnold, J. G.; Van Liew, M. W.; Bingner, R. L.; Harmel, R. D.; Veith, T. L. (2007). Transactions of the ASABE.50(3): $885-$ 900. doi: $10.13031 / 2013.23153$.

10. Moussa, R. (1996). Analytical Hayami solution for the diffusive wave flood routing problem with lateral inflow. Hydrological processes, 10(9), 1209-1227.

11. Nash, J. E.; Sutcliffe, J. V. (1970). River flow forecasting through conceptual models part I. A discussion of principles. Journal of
Hydrology. 10 (3): 1694(70)90255-6.

282-290. doi:10.1016/0022-

12. Prieto, C. et al. (2013). Propuesta de un modelo hidrológico agregado basado en ecuaciones generales de crecimiento. Aplicación a la cuenca del río Teifi (UK). Jornadas de Ingeniería del Agua. Valencia. Octubre de 2013.

13. Ritter, A.; Muñoz-Carpena, R. (2013). Performance evaluation of hydrological models: statistical significance for reducing subjectivity in goodness-offit assessments. Journal of Hydrology. 480 (1): 3345. doi:10.1016/j.jhydrol.2012.12.004.

14. Verhulst, P. F. (1838). "Notice sur la loi que la population suit dans son accroissement. Correspondance Mathematique et Physique Publiee par A." Quetelet 10: 113-121.

15. Vrugt, A., Gupta, H., Bastidas, A., Bouten, W., and Sorooshian, S. (2003). Effective and efficient algorithm for multiobjective optimization of hydrologic models Jasper. Water Resources Research, Vol. 39, No. 8, 1214, doi:10.1029/2002WR001746.

16. Yamazaki, D., S. Kanae, H. Kim, and T. Oki (2011). A physically based description of floodplain inundation dynamics in a global river routing model. Water Resource Research, 47, W04501, doi: 10.1029/2010WR009726. 